\title{
THE EFFECT OF TWO DIFFERENT ATTACHMENTS ON PATIENT SATISFACTION IN MANDIBULAR CLASS II AND III ACP RIDGES WITH SINGLE IMPLANT-RETAINED MANDIBULAR OVERDENTURES
}

\author{
Nouran Abdel Nabi*
}

\begin{abstract}
Background: The American collage of Prosthodontics (ACP) classified completely edentulous patients into four classes based on specific diagnostic criteria.

The aim of this randomized clinical trial is to compare patient satisfaction scores between ball and CMLOC attachment in class II and class III ACP for a single implant retained mandibular overdenture after 2 weeks of loading 1 and 2 year follow up.

Materials and Methods: Eighty completely edentulous patients were recruited from the outpatient clinic of Prosthodontics Department -Cairo University. Patients with Class II and III ACP classification were included in the study. All patients received a single implant in the mid line of the mandible. After a 3 month healing period, patients were randomized using sealed envelopes into ball attachment group and a CMLOC attachment group. Patient satisfaction questionnaire was used to record patient satisfaction for both groups 2 weeks after loading, then 1 and 2 years later.

Results: For the Ball group, there was no statistically significant difference - in patient satisfaction scores between both ACP classes at all follow up periods. As for the CMLOC group, no statistically significant difference in patient satisfaction scores was found between both classes 2 weeks after loading, while at 1 year follow up, patients with class III showed statistically significant better patient satisfaction and at 2 year follow up there was no significant difference between both classes.
\end{abstract}

Conclusion: The resiliency of the attachment and the associated denture base rotation seems to have a greater influence on patient satisfaction than the ACP classification.

* Assistant Professor Prosthodontics Department, Faculty of Dentistry, Cairo University. 


\section{INTRODUCTION}

The American collage of Prosthodontics (ACP) developed a classification system for completely edentulous patients which is based on specific diagnostic criteria. The classification divides completely edentulous patients into four classes; class I, II, III, and IV. In order to use this classification, the clinician has to follow a checklist, this check list is ordered according to the objectivity of assessment, not in order of significance. The check list consists of the following diagnostic criteria in descending order of objectivity; mandibular bone height measured radiographically, morphologic features of maxillary residual ridge, mandibular muscle attachment, maxilla-mandibular relationship, presence of conditions that requires pre-prosthetic surgery, inter-arch space, tongue anatomy, and modifying variables which are systemic disease, psychosocial factors or Tempromandibular Joint Disorder (TMD) ${ }^{1}$. Classifying completely edentulous patients according to a set criteria will aid in establishing a basis for diagnostic and treatment procedures, providing data for review of treatment outcomes, and simplifying communication in discussions of treatment with patients and colleagues ${ }^{2}$.

The ACP check list can be used during initial examination appointment, a single complex variable will classify the patient in high-level complex category. This "no tolerance" classification will emphasize the impact of each variable on the overall determination of the class, and the final classification is determined by the variable with the highest level of complexity, the more complex category will determine the class despite all other variables are favorable ${ }^{2}$.

Complete denture has been the most common treatment option for completely edentulous patients. Despite the numerous advantages that complete denture can offer ${ }^{3}$, many patients have complained from loss of retention and stability of mandibular complete dentures and that had an influential impact on patient satisfaction and patient's quality of life $\mathrm{4}^{4,5}$. Implant supported over dentures solved some of the problems of mandibular complete dentures. The MC Gill consensus 2002 and York consensus 2009 have stated that two implants installed in the mandible is considered to be the standard of care for completely edentulous patients ${ }^{6-8}$. Harder S et al 2011 and Cheng T et al 2012 have proved that a single implant installed in the mid line can be an efficient treatment option as two implants installed in the mandible ${ }^{9,10}$. Single implant retained mandibular overdenture is considered to be a cost effective treatment option with high success rates ${ }^{9}$ and reduction of post-operative complications especially to the elderly population, in addition to reduction in maintenance required when compared to two implant overdenture9

There are several types of attachment used to retain an implant over denture, they are mainly classified into splinted attachments such as bar attachments or un-splinted attachments such as ball or locator attachments ${ }^{11}$. The un-splinted attachments have been more commonly used than the splinted attachments owing to the smaller space requirements within the prosthesis, ease of cleaning, more economical, and lower sensitivity techniques $^{12,13}$.

Ball and socket attachment has been the most popular un-splinted attachment used to retain a mandibular overdenture, because its simplicity and cost effectiveness ${ }^{14}$. A newly introduced attachment made from polyetherketoneketone (PEKK) which is a member of the polyaryletherketones (PAEKs). Polyaryletherketones have the advantage of high chemical and mechanical resistance to wear and high tensile, fatigue and flexural strengths ${ }^{15}$. According to the manufacturer Cendres and Metaux, Polyetherketoneketone has $80 \%$ higher compressive strengths than other PAEK materials.

Recently, assessment of patient based outcome have been of great importance when considering 
dental implant therapy ${ }^{16}$. The majority of the clinical trials have focused on the evaluation of clinical, laboratory and radiological methods, all of this considered one component of the impact of the treatment but totally neglected the opinion and the attitude of the patient as a variable of treatment success. A patient oriented evaluation is very important regarding the outcome of the treatment, as it reveals the patient opinion regarding the comfort level of his denture, appearance, speech, and function which is very important to evaluate in order to determine patient satisfaction ${ }^{17,18}$. Patient satisfaction of completely edentulous patients is influenced by various factors including denture quality, the available denture bearing area, patient personality, and psychological well-being. The aim of this randomized clinical trial is to compare patient satisfaction scores between ball and CMLOC attachment in class II and class III ACP for a single implant retained mandibular overdenture 2 weeks after loading, 1 and 2 year follow up .

\section{MATERIALS AND METHODS}

Eighty completely edentulous patients were recruited from the outpatient clinic -Prosthodontics department-Cairo University. All patients were seeking implant treatment in their mandibular jaw as the chief compliant of those patients was loss of retention of their conventional mandibular dentures.

All included patients (age ranging from 50-69 years) were recruited following strict inclusion criteria; Glycosylated hemoglobin level $\geq 8$, patient with only class II and III according to Thomas Mc Garry 1999 $^{1}$ were included. Patients with any condition that would contra-indicate implant placement were excluded e.g patients with recent myocardial infarction and patients with intra-venous bisphosphate use, or patients with a buccolingual width that is less than $5 \mathrm{~mm}$ as any modification in the surgical technique during implant installation is considered to be a contra-indication.
There were three different phases for patient recruitment in this study, first phase was complete denture construction, then followed by second phase which is CBCT evaluation for identification of the ACP class and implant planning and then the third phase was signing the informed consent for implant installation which is considered the actual inclusion in the study. All patients were informed of the three phases at the beginning of the study, and patients were also informed that at the second phase (after CBCT evaluation) they can be excluded if they didn't meet the ACP classification, and for other reasons concerning the bucco-lingual width of anterior ridge if it is less than $5 \mathrm{~mm}$, as ridge splitting or grafting is considered to be one of the exclusion criteria.

The Prosthodontics diagnostic Index (PDI) for ACP classification was used in order to accurately classify all included patients into either class II or III (Figure 1). In order to fill the PDI for ACP classification, the patient's maxillary ridge morphology was tested by proper intra-oral finger palpation to examine the resistance of the tissues, and also to detect the presence of any redundant tissue. They are classified into type A, B, C and D, with A showing resistance to vertical and horizontal movement, while D having redundant tissues. The muscle attachment of the mandibular arch was also examined by proper intra oral palpation. Muscle attachment was classified into type A, B, C, D, and $\mathrm{E}$, where $\mathrm{A}$ showed adequate attached mucosa, while $\mathrm{E}$ showed no attached mucosa. In addition to the intra-oral palpation, intra-oral photographs of the maxillary and mandibular ridges were used to help in the classification. The tongue anatomy was one of the required items of the PDI chart, each patient had his tongue examined and was classified as large (occludes the interdental space), or hyperactive (retraced). Any condition that requires pre-prosthetic surgery was also recorded, as such condition can change the initial classification. The patient's systemic disease and oral condition was 
also recorded under "Modifier" item of the PDI chart, which is concerned with patients having TMD symptoms, paresthesia, dysesthesia, and psychological disturbance (Figure 1).

All included patients had new maxillary and mandibular complete denture fabricated following the conventional steps. The maxillo-mandibular relationship was examined during the steps of complete denture fabrication when the casts were mounted on the articulator, as this is one of the items included in the PDI for ACP classification. The inter-arch space was also evaluated while the casts were mounted on the articulator, the distance between the crest of the mandibular ridge to the occlusal plane of the maxillary arch was measured, and patients were then classified as with inter-arch space of $18-20 \mathrm{~mm}$ or requires surgical correction.

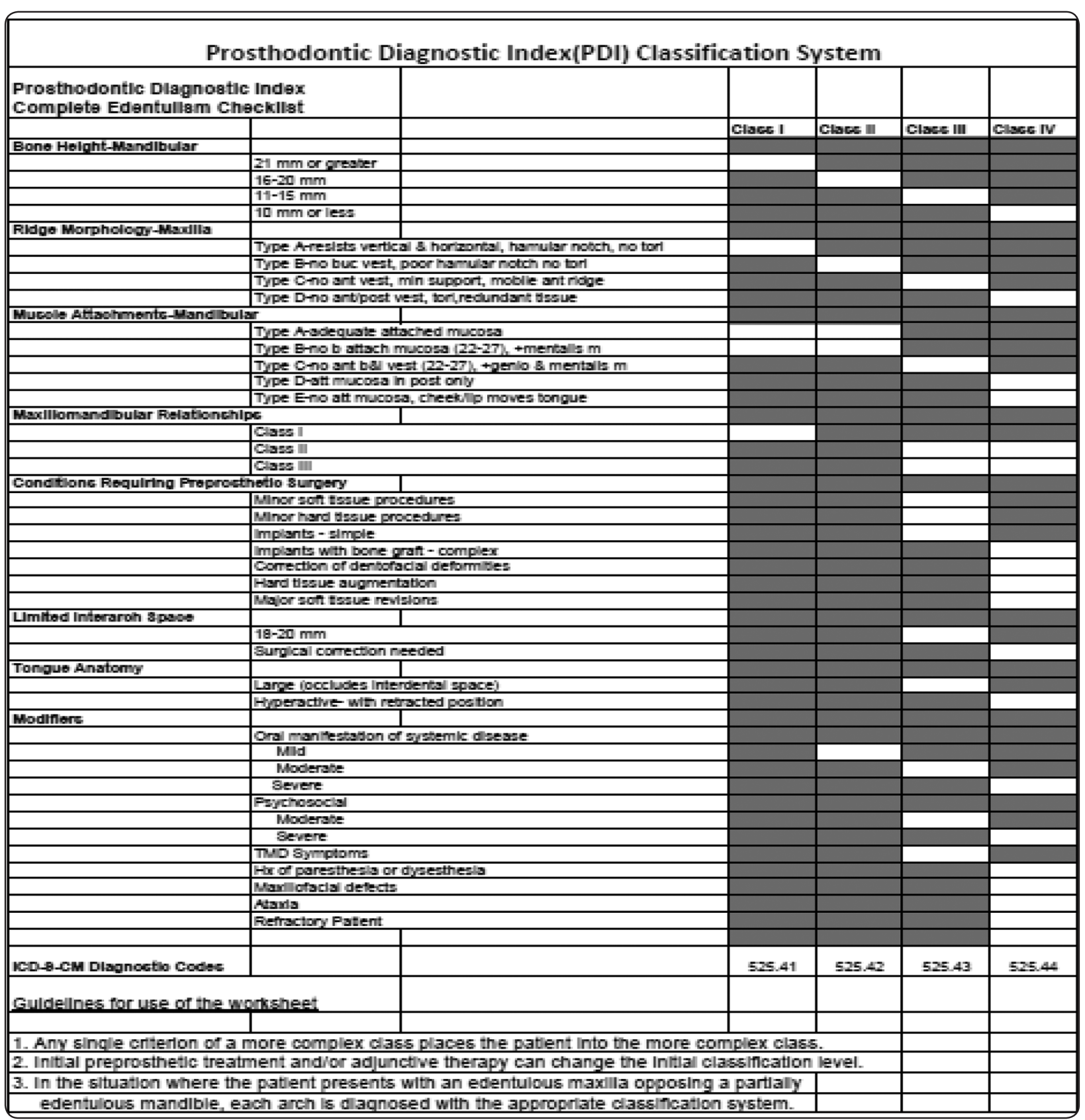

Fig. (1) The Prosthodontics Diagnostic Index (PDI) classification system 
Patients were allowed to adapt to their newly constructed dentures for a 3 week period. Following denture adaptation, all dentures were then duplicated to fabricate a transparent radiographic stent with radio-opaque acrylic resin placed in the anterior incisor area. A CBCT was performed for all patients while wearing the transparent radiographic stent with radio-opaque markers.

The panoramic view of the CBCT was used to measure the posterior bone height of the edentulous mandible, in order to classify all patients according to Mc Garry classification ${ }^{1}$ into class II or III. A line was drawn from the crest of the mandibular edentulous ridge to the base of the mandible and the least possible measurement was recorded (Figure 2, 3). Posterior bone height measurement for class II ranged from $16-20 \mathrm{~mm}$, while for class III ranged from 11-15mm. Bone height measurement of the mandible is considered to be an important diagnostic criteria of the PDI chart to accurately classify the patients into either class II and III.

At that stage all diagnostic criteria of the PDI chart was covered, each of the included patients had this PDI chart filled, the level of complexity of the diagnostic criteria would determine the class, so the more complex category will determine the class. Only patients with class II and III were included in this study, all the 80 included patients were either class II or III.

The CBCT was also used for proper planning for implant installation, as the buccal and lingual bone thickness was properly evaluated by the help of the radio-opaque marker (Figure 4).

\section{Implant installation}

The radiographic stent was then modified into a surgical stent by making a wide hole at the central incisor area in the place corresponding to implant installation. All patients were instructed to be on $1 \mathrm{gm}$ of amoxicillin 1 day prior to the surgery. A small crestal incision was made in the central incisor area. All implants installed in this study were Zimmer

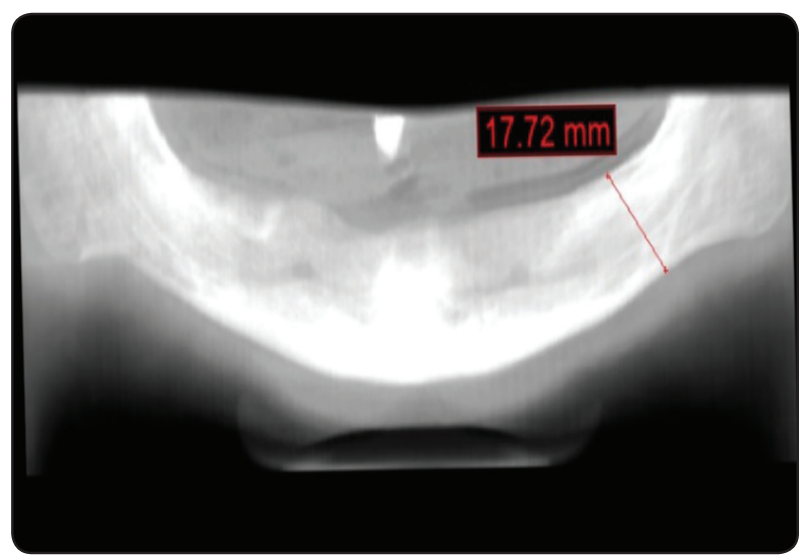

Fig. (2) Showing the panoramic view of CBCT, and measurement for Class II ACP

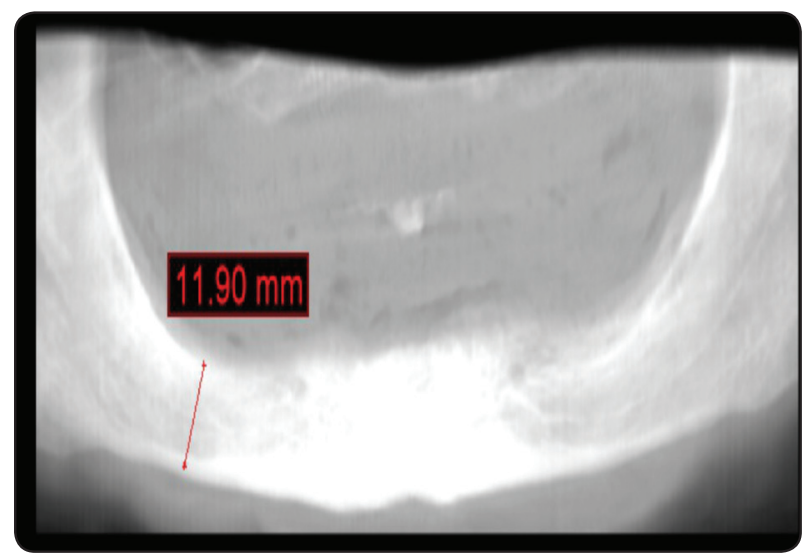

Fig. (3) Showing the panoramic view of CBCT, and measurement for Class II ACP

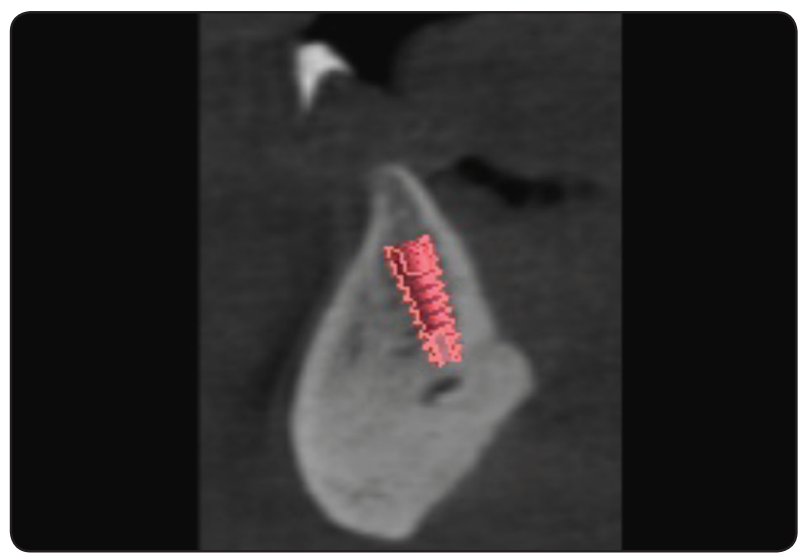

Fig. (4) Showing cross section of implant planning 
dental implants ${ }^{*}$ and were $3.7 \mathrm{~mm}$ in diameter and $10 \mathrm{~mm}$ in length. Drilling was carried out according to the manufacturer instructions, using the Zimmer kit. All installed implants were left to heal for a 3 month period and the patient's denture was properly relieved using soft liner GC Soft-Liner**

At the end of the healing phase 6 patients reported implant failure, and 3 patients were considered as drop-outs. A total of 71 patients were then ready to receive the attachment.

\section{Attachment installation and pick up}

Two attachments were being used in this study; Ball attachment with a nylon matrix (Zimmer dental implants), and the CMLOC attachment with a PEKK matrix (Cendres \& Meteaux). After the 3 month healing period, patients were randomized using sealed envelopes into; first group of patients receiving ball attachment, and the second group receiving the CM LOC attachment. Seventy one patients were randomized into two groups as the sealed envelopes were prepared at the beginning of the study before drop outs; 34 patients in the ball group, and 37 patients in the CM LOC group.

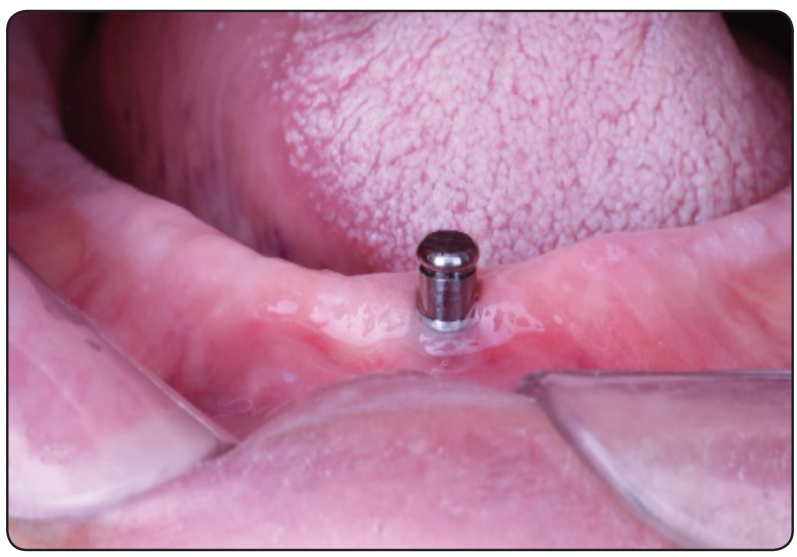

Fig. (5) Showing CMLOC attachment

\footnotetext{
* Implants ZDI, Tapered screw vent Indiana America

** GC Corporation, Tokyo, Japan
}

Both attachments were screwed to the implant with a torque of $30 \mathrm{~N}$, and the corresponding matrix on top of it (Figure 5, 6). The mandibular denture was then modified by cutting a small hole in the area corresponding to the attachment and a red die was placed on the fitting surface of the modified denture to ensure that there was no interference between the acrylic resin and the attachment matrix. The mandibular denture was then checked for proper seating, and the occlusion with the maxillary denture was properly checked.

A small piece of rubber dam was used to block the undercuts present in both attachments. The denture was then properly seated in place then a soft mix of self-cure acrylic resin was then added to the hole of the modified denture, the patient was then asked to bite gently in centric relation.

After complete setting of acrylic resin the denture was removed and pick up of the matrix was checked (Figure 7, 8). All excess acrylic resin was removed and then polished. Patients were recalled 3 days after pick up to check if there were any premature contacts or areas that required relief. This procedure was carried out for both attachments used in this study.

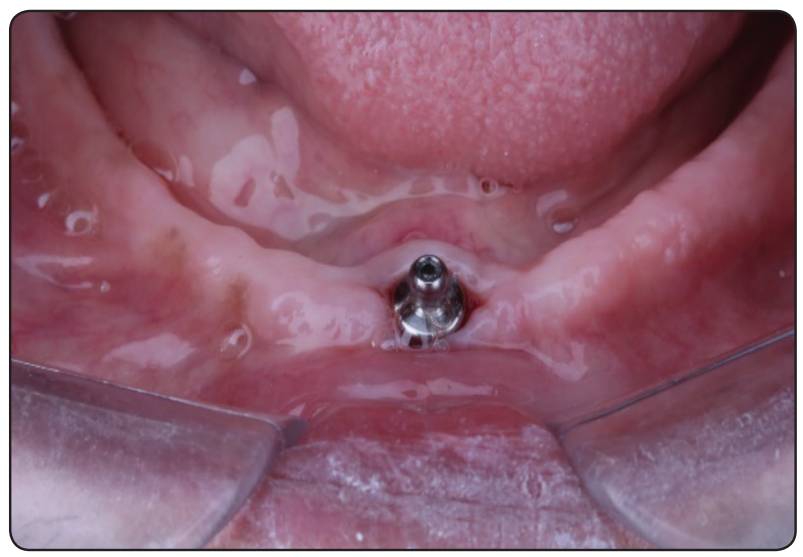

Fig. (6) Showing Ball attachment 


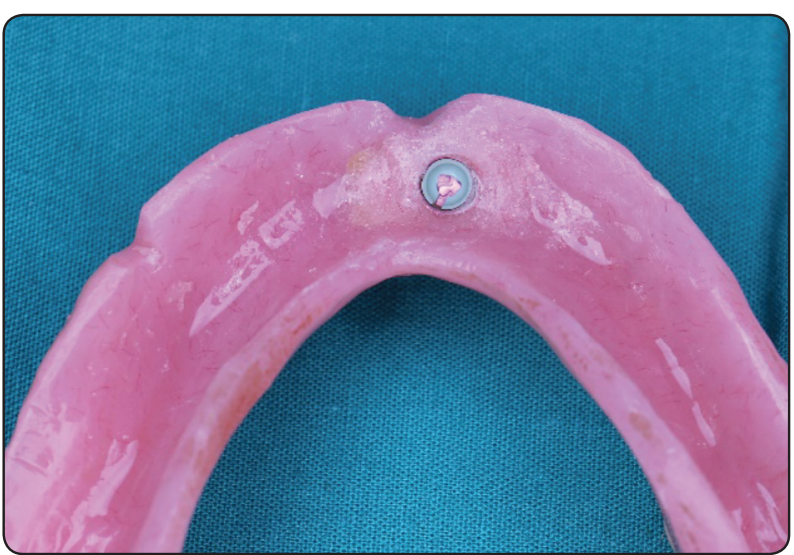

Fig. (7) Showing PEEK matrix after pick up

A Patient satisfaction questionnaire ${ }^{19}$ was used to record patient satisfaction for both groups of patients at 2 weeks interval after delivery, 1 year follow up and 2 years follow up (Figure 9). The patient satisfaction chart used in this study consisted of 11 questions, and each question had four options,

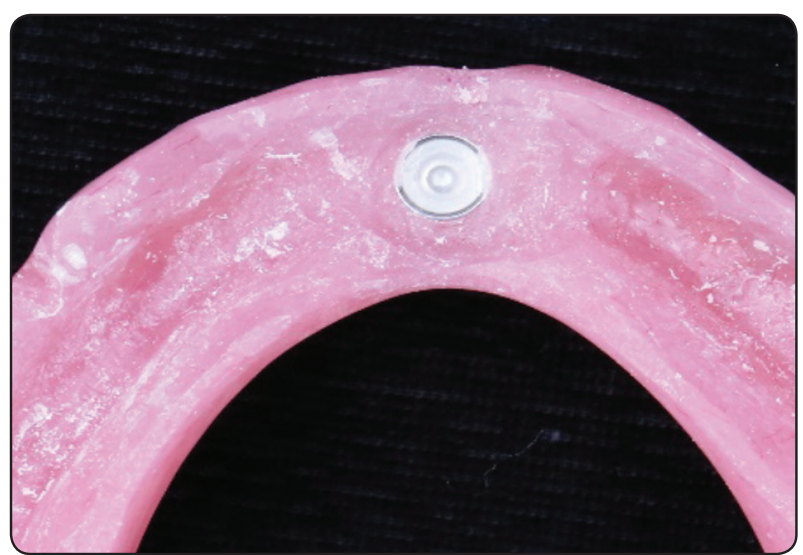

Fig. (8) Showing Nylon Matrix after pick up

scores from 1 to 4 was given for each option (1=Very well/pleased, 4=Poor/not pleased at all), A score for each question was recorded and then a total score for the 11 questions was calculated. Lower scores denoted higher patient satisfaction (Figure 9).

At the end of first year follow up, a total of 5

\section{Matrix after pick up}

\begin{tabular}{|c|c|c|}
\hline Questions & & score \\
\hline 1- How do you rate the appearance of your denture? & Very well $=1$, Well $=2$, Poor $=3$, very poor $=4$ & \\
\hline $\begin{array}{l}\text { 2-How do you rate the quality of expression and } \\
\text { phonetics? }\end{array}$ & Very well $=1$, Well $=2$, Poor $=3$, very poor $=4$ & \\
\hline $\begin{array}{l}\text { 3-How do you rate the removal and insertion of your } \\
\text { denture? }\end{array}$ & Very well $=1$, Well $=2$, Poor $=3$, very poor $=4$ & \\
\hline $\begin{array}{l}\text { 4-How do you feel about the pleasure you get from } \\
\text { food, compared with the time when you had natural } \\
\text { teeth? }\end{array}$ & $\begin{array}{l}\text { Very pleased }=1 \quad \text { Pleased }=2 \text { Not pleased }=3 \\
\text { Not pleased at all }=4\end{array}$ & \\
\hline $\begin{array}{l}\text { 5-With respect to eating, how satisfied are you with } \\
\text { your dentures? }\end{array}$ & $\begin{array}{l}\text { Very satisfied }=1 \quad \text { Satisfied }=2 \quad \text { Not satisfied } \\
=3 \quad \text { Not satisfied at all }=4\end{array}$ & \\
\hline $\begin{array}{l}\text { 6-With respect to your professional performance, } \\
\text { how satisfied are you with your oral conditions? }\end{array}$ & $\begin{array}{l}\text { Very satisfied }=1 \quad \text { Satisfied }=2 \\
\text { satisfied }=3 \quad \text { Not satisfied at all }=4\end{array}$ & \\
\hline 7-How well your upper denture stay at place? & Very well $=1$, Well $=2$, Poor $=3$, very poor $=4$ & \\
\hline 8-How well your lower denture stay at place? & Very well $=1$, Well $=2$, Poor $=3$, very poor $=4$ & \\
\hline 9-How comfortable is your upper complete denture? & Very well $=1$, Well $=2$, Poor $=3$, very poor $=4$ & \\
\hline 10- How comfortable is your lower denture? & Very well $=1$, Well $=2$, Poor $=3$, very poor $=4$ & \\
\hline 11-How satisfied are you with your dentures? & Very well $=1$, Well $=2$, Poor $=3$, very poor $=4$ & \\
\hline Total score & & \\
\hline
\end{tabular}

Fig. (9): Patient satisfaction chart ${ }^{19}$, consists of 11 questions, and each question each has four options with the best score $=1$ and worst $\operatorname{score}=4$, a total score was calculated for each patient. 
patients were considered drop outs 2 patients from the ball group, and 3 patients from CM LOC group. 1 patient from the ball group died. The reason behind the drop outs that patients were hospitalized and were not able to attend follow ups. So the total number of patients for the ball group was 31 patients, 34 patients for the CMLOC group and a total of 65 patients by the end of the first year follow up (Table 1).

At the end of the second year follow up, a total of 12 patients were considered as drop outs; 4 patients from the ball group, and 8 patients from the $\mathrm{CM}$ LOC group. 2 patients died by the end of the second year, 1 patient from ball group, and 1 patient from CM LOC group. The reason for drop outs was that some patients have moved out of Cairo, and some were hospitalized and so were not able to attend the follow ups. So a total of 26 patients for the ball group, 25 patients for the CM LOC group and a total of 51 patients by the end of the second year follow up (Table 2).

Data were statistically described in terms of mean \pm standard deviation $( \pm$ SD). Numerical data were tested for the normal assumption using Kolmogorov Smirnov test. Comparison between the study groups was done using Student $t$ test for independent samples in comparing 2 groups of normally distributed data. $p$ values less than 0.05 was considered statistically significant. All statistical calculations were done using computer program IBM SPSS (Statistical Package for the Social Science; IBM Corp, Armonk, NY, USA) release 22 for Microsoft Windows.

TABLE (1): Showing the number of patients by the end of the first year follow up.

\begin{tabular}{|l|l|l|l|}
\hline & $\begin{array}{l}\text { Ball group } \\
(34 \text { patients })\end{array}$ & $\begin{array}{l}\text { CM LOC group } \\
(37 \text { patients })\end{array}$ & $\begin{array}{l}\text { Total number } \\
(71 \text { patients })\end{array}$ \\
\hline Drop out after 1 year & $\begin{array}{l}2 \text { patients; } \\
\text { both class II }\end{array}$ & $\begin{array}{l}3 \text { patients ; } \\
1 \text { patient class II } \\
2 \text { patients class III }\end{array}$ \\
\hline patients who passed away & $\begin{array}{l}1 \text { patient ; } \\
1 \text { patient Class III }\end{array}$ & 0 & 1 patient \\
\hline Total number & 31 patients & 34 patients & 65 patients \\
\hline
\end{tabular}

TABLE (2): Showing distribution of patients by the end of the second year follow up.

\begin{tabular}{|l|l|l|l|}
\hline & $\begin{array}{l}\text { Ball group } \\
(31 \text { patients })\end{array}$ & $\begin{array}{l}\text { CM LOC group } \\
(34 \text { patients })\end{array}$ & $\begin{array}{l}\text { Total number } \\
(65 \text { patients })\end{array}$ \\
\hline Drop out after 2 year & $\begin{array}{l}\text { 4 patients; } \\
2 \text { patients class II } \\
2 \text { patient class III }\end{array}$ & $\begin{array}{l}\text { 8 patients; } \\
4 \text { patients class II } \\
4 \text { patients class III }\end{array}$ & patients \\
\hline patients who passed away & $\begin{array}{l}\text { 1 patient; } \\
\text { class III }\end{array}$ & $\begin{array}{l}1 \text { patient; } \\
\text { class II }\end{array}$ & 2 patients \\
\hline Total number & 26 patients & 25 patient & 51 patients \\
\hline
\end{tabular}




\section{RESULTS}

\section{Ball attachment group}

At 2 weeks from loading there was no statistically significant difference $(\mathrm{p}=0.930)$ between mean patient satisfaction scores for patients with class II ACP (24.36 \pm 7.352$)$ and patients with class III ACP (24.15 \pm 5.851$)$. Patient satisfaction scores at 2 weeks from loading seemed to be the highest scores recorded (which signifies the least patient satisfaction ) when compared to 1 and 2 year follow ups, with nearly equal mean scores for both class II and class III patients. While at the first year follow

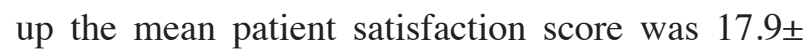
5.587 for class II patients, and $18.35 \pm 5.787$ for class III patients . Class II patients have shown a slightly better patient satisfaction score than class III patients however it was statistically insignificant $(p=0.844)$. Similarly at the second year follow up the mean patient satisfaction score was $17.44 \pm 4.362$ for class II patients, and 18.18 \pm 4.852 for class III patients, Still patients with class II have shown a slight greater patient satisfaction than class III, yet it remained statistically insignificant $(\mathrm{p}=0.707)$ (Table 3), ( Figure 10).

\section{CMLOC Group}

At 2 weeks from loading there was no statistically significant difference $(p=0.627)$ between the mean patient satisfaction scores in patients with class II $(21.67 \pm 6.264)$ and patients with class III $(20.68 \pm 5.406)$. However at the first year follow up, the mean patient satisfaction scores in patients with class III $(16.78 \pm 5.012)$ were significantly better $(\mathrm{p}=0.042)$ than in patients with class II $(20.69 \pm 5.105)$. At the second year follow up, the mean patient satisfaction scores improved in patients with class II $(16.5 \pm 4.720)$ who were eventually more satisfied than patients with class III whose scores declined to $19.33 \pm 6.510$. However this difference was statistically insignificant $(\mathrm{p}=0.250)$. (Table 4), (Figure 11).

TABLE (3): Number of patient, mean scores and standard deviation of patient satisfaction at 2 weeks from loading, 1 year follow up, and 2 year follow up for patients of class II, \& class III for patients with ball attachment group. SD: standard deviation, $\mathrm{P} \leq 0.05$ is considered statistically significant.

\begin{tabular}{|l|l|l|l|l|}
\hline \multirow{2}{*}{ ACP } & & $\begin{array}{l}\text { patient satisfaction at } 2 \\
\text { weeks loading }\end{array}$ & $\begin{array}{l}\text { Patient satisfaction } \\
\text { at 1 year -follow up }\end{array}$ & $\begin{array}{l}\text { Patient satisfaction at } \\
\text { 2 years-follow up }\end{array}$ \\
\hline \multirow{5}{*}{ Class II } & Number & 13 & 11 & 9 \\
\cline { 2 - 6 } & Mean & 24.36 & 17.9 & 17.44 \\
\cline { 2 - 6 } & SD & 7.352 & 5.587 & 4.362 \\
\hline \multirow{3}{*}{ Class III } & Number & 21 & 20 & 17 \\
\cline { 2 - 6 } & Mean & 24.15 & 18.35 & 18.18 \\
\cline { 2 - 6 } & SD & 5.851 & 5.787 & 4.825 \\
\hline & p value & 0.930 & 0.844 & 0.707 \\
\hline
\end{tabular}


TABLE (4): Number of patient, mean scores and standard deviation of patient satisfaction at 2 weeks from loading, 1 year follow up, and 2 year follow up for patients of class II, \& class III for patients with CM LOC attachment group. SD: standard deviation, $\mathrm{P} \leq 0.05$ is considered statistically significant.

\begin{tabular}{|l|l|l|l|l|}
\hline \multirow{2}{*}{ ACP } & & $\begin{array}{l}\text { patients at 2 weeks } \\
\text { from loading }\end{array}$ & $\begin{array}{l}\text { Patient satisfaction } \\
\text { at 1 year -follow up }\end{array}$ & $\begin{array}{l}\text { Patient satisfaction at } \\
\text { 2 years-follow up }\end{array}$ \\
\hline \multirow{5}{*}{ Class II } & Number & 16 & 15 & 10 \\
\cline { 2 - 5 } & Mean & 21.67 & 20.69 & 16.5 \\
\cline { 2 - 5 } & SD & 6.264 & 5.105 & 4.720 \\
\hline \multirow{3}{*}{ Class III } & Number & 21 & 19 & 15 \\
\cline { 2 - 5 } & Mean & 20.68 & 16.78 & 19.33 \\
\cline { 2 - 5 } & SD & 5.406 & 5.012 & 6.510 \\
\hline & p value & 0.627 & $0.042^{*}$ & 0.250 \\
\hline
\end{tabular}

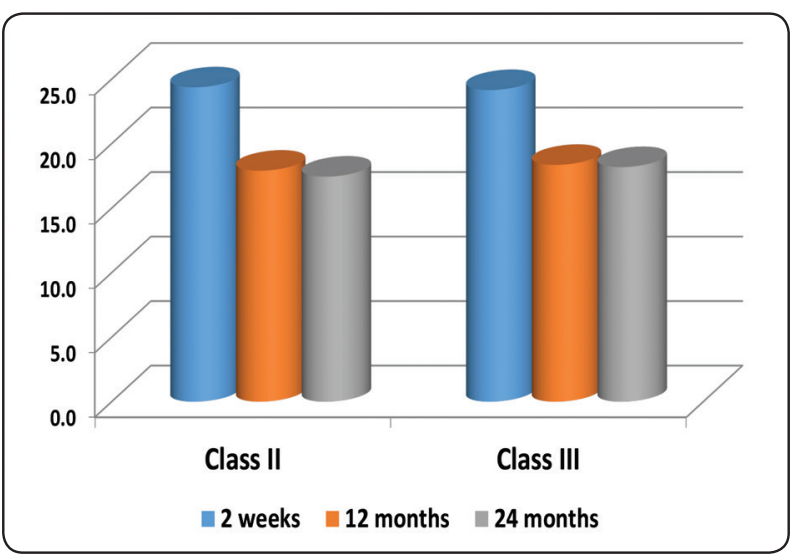

Fig. (10): Mean patient satisfaction score between 2 weeks from loading, 1 and 2 year follow up for Class II and class III among Ball attachment group.

\section{DISCUSSION}

The ACP classification has been used in several studies to describe the condition of the alveolar ridge whether developed, moderately developed, resorbed, severely resorbed ${ }^{20}$. Very few studies have reported the relation between patient satisfaction and ACP classes for implant supported overdentures ${ }^{21}$. That was the reason why we have conducted our randomized clinical trial to compare patient

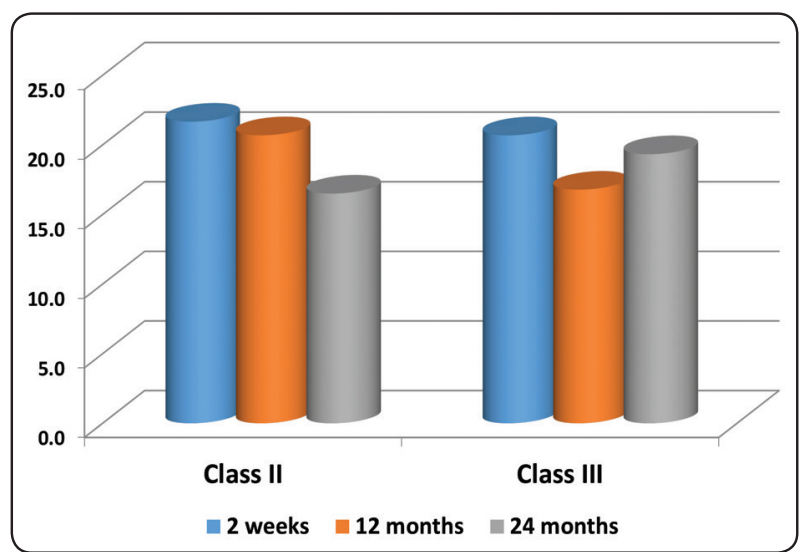

Fig. (11): Mean patient satisfaction score between 2 weeks from loading , 1 and 2 year follow up for Class II and class III among CM LOC attachment group

satisfaction scores between two ACP classes; Class II and III for a single implant retained mandibular overdenture when using two different attachments; ball attachment and CM LOC attachment.

Developing a proper and sufficient recruitment strategy in Randomized Clinical Trials (RCT) is considered to be very important, as insufficient recruitment of patients will have an impact on the results of most RCTs. In the present RCT 
recruitment of patients were carried out through three different phases; first phase was complete denture construction, then second phase was CBCT evaluation and then third phase signing of the informed consent for implant installation. Mc Henry et al $\mathbf{2 0 1 5}^{\mathbf{2 2}}$ developed a four strategy for proper patient recruitment and retention; the first focused on how to effectively access the appropriate population, the second dealt with patient communication and trust building, the third focused on providing security and comfort to manage patient anxiety. All clinical steps of the present trial were explained to the patients at the initial appointment - in a face to face discussion as this has proved to be more effective than signing initially an informed consent ${ }^{23}$. The reason that actual inclusion of patients and signing of consent was postponed to the third phase, as patient compliance and commitment was being evaluated by their attendance to the different steps of complete denture construction, and CBCT evaluation, as this will give an indication if those patients will attend the future follow ups in addition to that rapport and trust building was being achieved through the different steps of complete denture fabrication. CBCT evaluation was carried out after complete denture construction, so that it can be used for two purposes; to classify the patient according to MC Garry ${ }^{\mathbf{1}}$, and to be used for proper implant planning by making use of duplicating the patients' complete denture into a radiographic stent with radio-opaque marker. This actually saved the patients from being exposed to several doses of $\mathrm{x}$ rays, an initial panoramic $\mathrm{x}$ ray and then $\mathrm{CBCT}$ radiograph.

Patients with class I ACP classification were not included in this study because according to MC Garry ${ }^{1}$, the posterior bone height of the mandible range would be greater than $21 \mathrm{~mm}$, so those patients will most probably be satisfied with their conventional mandibular complete dentures and would not need implant installation to improve their retention Also patients with class IV ACP classification were excluded because their posterior bone will offer little horizontal stability so would require installation of two or more implants to improve retention of their mandibular denture. Only patients with ACP Class II and III were included.

The measurement of the posterior bone height of the mandible is considered to be the most easily identified objective criteria of the edentulous mandible ${ }^{24}$. As the continued decrease in bone volume will affect denture bearing area, tissue remaining for reconstruction, facial muscle support and attachment, total facial height ${ }^{25}$ and ridge morphology. The least posterior vertical bone height for patients with class II was from 16$20 \mathrm{~mm}$, while that for class III was from $11-15 \mathrm{~mm}$. When classifying patients included in this study all other diagnostic criteria was considered but mainly posterior ridge height measurement was the major determinant for classifying patients.

Studies have reported that there is a correlation between patient satisfaction, quality of life and denture or patient related factors ${ }^{26,27}$. Denture related factors include denture retention, stability, occlusion and appearance ${ }^{26-32}$. Patient related factors include age $^{29}$, case severity, denturesupporting tissue shape ${ }^{26,33}$, and previous denture experience $^{31}$. In the present clinical trial, the patient satisfaction questionnaire ${ }^{19}$ used consisted of 11 questions, having 4 different options with score of 1 (maximum satisfaction) to 4 (least satisfaction). This questionnaire was used because it is simple, and could be easily translated into Arabic and it also includes all of the questions that would evaluate denture related factors including; appearance, mastication, retention of maxillary and mandibular dentures, and overall satisfaction.

Attachments are considered to be very important for the success or failure of an implant-retained overdenture as they play a great role in improving its retention and stability. Attachments are mainly classified into rigid and resilient. Resilient 
attachments will allow some freedom of rotation to release the stresses around the installed implants ${ }^{34}$. Denture rotation may cause food entrapment underneath the denture especially when chewing on anterior teeth, which will later influence patient satisfaction $^{35}$. To prevent rotational movements some of the principles that enhance complete denture retention, support and stability should be applied, such as maximum extension of the denture base, correct position of teeth, and the polished surface of the external surface of the denture. In addition to that, Kimoto $2009^{35}$ have reported that increasing the length of the denture flanges is likely to decrease rotational movements.

It was found that for the ball attachment group there was no statistically significant difference in patient satisfaction scores between class II and class III at all follow-up periods with a slight yet nonsignificant greater satisfaction for patients with class II in the first and second year follow ups. As for the CMLOC attachment group, there was no significant difference between the two groups 2 weeks after loading, however at the first year follow up, class III patients were significantly more satisfied than class II patients. At the second year follow up, class II patients were slightly more satisfied yet there was no significant difference between the two groups. .

The reason for such results is that there tends to be some difference in the mode of action between the ball and CMLOC attachment although both attachments seemed to have improved the retention of the patient's denture. For the ball attachment with its nylon cap there tends to be no vertical resiliency during movement ${ }^{36}$ resulting in fewer denture base rotation $^{37}$ during mastication on posterior teeth which has increased patient satisfaction in both classes to the extent that they showed comparable satisfaction scores. This was very well explained by the insignificant difference and nearly equal mean patient satisfaction scores between the two classes at 2 weeks from loading. However despite this statistically insignificant difference, patients with ACP class II were always slightly more satisfied than patients with class III. This could be attributed to the alveolar ridge height which is obviously greater in Class II. The greater the vertical height of the alveolar ridge, the greater the surface area on which the overdenture rests which will consequently improve retention ${ }^{38}$, stability and support that would likely to enhance speech, chewing and appearance. In addition to that, the length of the denture flange was probably longer than that of patients with class III, which may have also decreased denture base rotation $^{35}$

As for the CMLOC attachment, it has a PEKK matrix design with a slot in the matrix. This slot expands upon loading, thus resulting in more vertical resiliency that would allow for denture base rotation. The reason patients with ACP class III have shown a greater patient satisfaction than those of class II, 2 weeks after loading, and it was significant in the first year was mainly because these patients have experienced more denture movement with their conventional complete dentures compared to Class II patients due to the decreased posterior vertical bone height. The installation of a single implant and incorporation of the CMLOC attachment seemed to significantly improve the denture's retention in both, classes II and III patients, however the impact of this denture's retention improvement on patient satisfaction was greater in patients with class III than in class II patients to the extent that it even surpassed the effect of denture base rotation. In the second year follow up however there was no significant difference in patient satisfaction between the two ACP classes, with a slightly better patient satisfaction for patients with class II ACP. It seems that eventually patients in both classes adapted to their dentures well, yet denture base rotation was still less in class II patients due to the longer denture flanges and greater denture bearing area. This may have resulted in the slight better satisfaction experienced by Class II patients, but as mentioned earlier this difference was insignificant. 
It can be concluded from the present study that the resiliency of the attachment and the denture base rotation will have a greater influence on patient satisfaction than the ACP classification itself. This comes in agreement with Kimoto K 2005 ${ }^{39}$ and Pan S. et al 2010 21 that concluded that mandibular bone height has no effect on patient satisfaction. The ball attachment used in a single implant retained mandibular overdenture showed no significant difference in patient satisfaction between ACP class II and III over the 2 year follow up. While the use of a CM LOC attachment in a single implant retained overdenture have resulted in significantly better patient satisfaction for patients with class III ACP when compared to patient with class II ACP in the first year follow up with no significant difference over the second year follow up.

A limitation of this study is that actual retention values of the ball and CMLOC attachments, as well as, the magnitude of denture base movement should have been recorded to objectively justify the results obtained and objectively prove the influence of attachment retention and denture base movement on patient satisfaction.

Future recommendations is to compare patient satisfaction in patients with different ACP classes using different number of implants (2, 3 and 4 ) for implant retained over dentures, with different attachments in order to detect the influence of implant number and denture rotation on patient satisfaction.

\section{REFERENCES}

1. McGarry TJ, Nimmo A, Skiba JF, Ahlstrom R, Smith C, Koumjian J. Classification system for completely edentuluism. J. Prosthodont 1999; 8:27-39.

2. Mazurat R.D, Mazurat NM. Communicating complexity: using a diagnostic classification system for edentulous patients. J Can Dent Assoc 2003; 69(8):511-4.

3. Jenei A, Sandor J, Hegedus C, Bagyi K, Nagyi K, Kiss C, Szabo G, Marton I J. Oral health-related quality of life after prosthetic rehabilitation: a longitudinal study with the OHIP questionnaire," Health Qual Life Outcomes of 2015; 13(1): p. 99-106.

4. John MT, Szentpetery A, J Steele JG. Association between factors related to the time of wearing complete dentures and oral health-related quality of life in patients who maintained a recall. Int J Prosthodont 2007 ;20( 1):31-36.

5. Eyamaga E, Sato Y, Sminakuchi S, A structural equation model relating oral condition, denture quality, chewing ability, satisfaction, and oral health-related quality of life in complete denture wearers. J Dent 2013;41, (8): 710-717.

6. Thomason JM, Kelly SA, Bendkowski A, Ellis JS. Two implant retained overdentures - A review of the literature supporting the McGill and York consensus statements. J Dent 2012; 40:22-34.

7. Thomason JM. The McGill consensus statement on overdentures. Mandibular 2-implant overdentures as first choice standard of care for edentulous patients. Eur $\mathbf{J}$ Prosthodont Restor Dent 2002; 10:95-6.

8. Feine JS, Carlsson GE, Awad MA, Chehade A, Duncan WJ, Gizani S, et al. The McGill consensus statement on overdentures. Quintessence Int 2003; 34:78-9.

9. Harder S, Wolfart S, Egert C, Kern M. Three-year clinical outcome of single implant-retained mandibular overdentures - Results of preliminary prospective study. J Dent 2011; 39:656-61.

10. Cheng T, Sun G, Huo J, He X, Wang Y, Ren YF. Patient satisfaction and masticatory efficiency of single implant-retained mandibular overdentures using the stud and magnetic attachments. J Dent 2012; 40:1018-23.

11. Sadowsky S.J. Treatment consideration for maxillary implant overdentures: a systemic review. J Prosthet Dent 2007; 97: 340-348.

12. Trakas T., Michalakis K, Kang K, Hirayama H. Attachment systems for implant retained overdentures: a literature review. Implant Dent. 2006; 15:24-34.

13. Alsabeeha NHM, Payne AGT, Swain MV. Attachment systems for mandibular two-implant overdentures: a review of in vitro investigations on retention and wear features. Int J Prosthodont 2009; 22: 429-440.

14. Fenlon MR, Palmer RM, Palmer P, Newton J T, Sherriff $\mathrm{M}$ : A prospective study of single stage surgery for implant supported overdentures. Clin Oral Implants Res 2002; 13:365-370. 
15. Fuhrmann G, Steiner M, Freitag-Wolf S, Kern M. Resin bonding to three types of polyaryletherketones (PAEKs)durability and influence of surface conditioning. Dent. Mater.2014 30,357-363.

16. McGrath C, Lam O, Lang N. An evidence-based review of patient-reported outcome measures in dental implant research among dentate subjects. J Clin Periodontol. 2012; 39(Suppl 12):193-201.

17. Zitzmann NU, Marinello CP. Treatment outcomes of fixed or removable implant-supported prostheses in the edentulous maxilla. Part I: Patients 'assessments. J Prosthet Dent 2000; 83:424-33.

18. Pace-Balzan A, Butterworth CJ, Dawson LJ, Lowe D, Rogers SN. The further development and validation of the Liverpool Oral Rehabilitation Questionnaire (LORQ) version 3: A cross-sectional survey of patients referred to a dental hospital for removable prostheses replacement. J Prosthet Dent 2008; 99:233-42.

19. Fenlon MR., Sherriff M. Investigation of new complete denture quality and patients satisfaction with and use of dentures after two years. J Dent 2004; 32(4):327-33.

20. Thu KM, Kanazawa M., Thuy VL, Asami M, Sato D, Minakuchi S. Clinical trend of retention for mandibular single implant overdentures using locator attachment. J Dent Oral Disord Ther. 2019; 10(3):193-197.

21. Pan S, Dagenais M, Thomason JM, Awad M, Emami E, Kimoto S, Stephanie DW, Feine JS. Dose mandibular edentulous bone height affect prosthetic treatment success. J Dent 2010; 38:899-907.

22. McHenry JC, Insel KC, Einstein GO, Vidrine AN, Koerner KM, Morrow DG. Recruitment of older adults: Success may be in the details. Gerontologist. 2015;55(5):845-53 .

23. Nishimura A, Carey J, Erwin PJ, Tilburt JC, Murad MH, McCormick JB. Improving understanding in the research informed consent process: a systematic review of 54 interventions tested in randomized control trials. BMC Med Ethics 2013 ;14(1):28.

24. Tallgren A. The continuing reduction of the residual alveolar ridges in complete denture wearers: $\mathrm{h}$ mixedlongitudinal study covering 25 years. J Prosthet Dent 1972; 27:120-132.

25. Davis DM. Developing an analoguelsubstitute for the mandibular denture-bearing area. In Zarb, Bolender, Carlsson (eds). Prosthodontic Treatment for Edentulous
Patients (ed 11). St. Louis, MO. h4osby-Year Book, Inc, 1997, 162-173.

26. Yamaga E, Sato Y, a Minakuchi S, A structural equation model relating oral condition, denture quality, chewing ability, satisfaction, and oral health-related quality of life in complete denture wearers.J Dent 2013;41(8), 710-717.

27. Cerutti-Kopplin D, Emami E. Hilgert JB, Hugo FN, Rivaldo E, Padilha DM. Predictors of satisfaction with dentures in a cohort of individuals wearing old dentures: functional quality or patient-reported measures? J. Prosthodont 2017; 26, (3), 196-200.

28. Alfadda SA, Al-Fallaj HA, Al-Banyan HA, ,Al-Kadhi RM, A clinical investigation of the relationship between the quality of conventional complete dentures and the patients' quality of life, Saudi Dent J 2015;27(2): 93-98.

29. Celebic A, Knezovic-Zlataric D, Papic M, Carek V, Baucic I, , Stipetic J, Factors related to patient satisfaction with complete denture therapy, J Gerontol A Biol Sci Med Sci 2003; 58 (10): M948-M953.

30. Chen Y, Yang Y, Chen J, Lee H E, Lin YC, Ebinger J, Chou TM., The impact of complete dentures on the oral health-related quality of life among the elderly, J. Dent Sci 2012; 7, (3): 289-295.

31. Van Waas MAJ, "Determinants of dissatisfaction with dentures: a multiple regression analysis," J Prosthet Dent 1990; 64(5):569-572.

32. Komagamine Y, Kanazawa M, Kaiba Y, Sato Y, Minakuchi S, Y. Sasaki Y. Association between self-assessment of complete dentures and oral health-related quality of life. J. Oral Rehabil. 2012; 39 (11): 847-857.

33. Kurushima Y, Matsuda K, Enoki K, Ikebe K , Maeda Y. Does case severity make a difference to clinical improvement following complete denture treatment? Int. J Prosthodont.2015; 28 (2):161-166.

34. Oetterli, M, Kiener, P, Mericske-Stern R. A longitudinal study on mandibular implants supporting an overdenture: the influence of retention mechanism and anatomicprosthetic variables on peri-implant parameters. Int. J Prosthodont 2001; 14: 536-542.

35. Kimoto S, Pan S, Drolet N, Feine JS. Rotational movements of mandibular two-implant overdentures. Clin. Oral Impl. Res.2009;20:838-843.

36. Assuncao WG, Barao VA, Tabata LF, Capello de Sousa A, Gomes EA, Delben JA. Comparison between complete 
denture and implant-retained overdenture: Effect of different mucosa thickness and resiliency on stress distribution. Gerodontology. 2009; 26:273-281.

37. Maeda Y, Horisaka M, Yagi K. Biomechanical rationale for a single implant retained mandibular overdenture: an in vitro study. Clin Oral Implants Res 2008; 19:271-275.

38. Allen PF, McMillan AS. A review of the functional and psychosocial outcomes of edentulousness treated with complete replacement dentures. J. Can. Dent.Assoc. 2003;69. 662a-d.

39. Kimoto K, Garrett NR. Effect of mandibular ridge height on patients' perceptions with mandibular conventional and implant-assisted overdentures. Int J Oral Max Impl. $2005 ; 20: 762-8$ 